\title{
Program Komputer sebagai Alat Bantu Perencanaan Rangka Batang Baja
}

\section{Oleh : Bachnas}

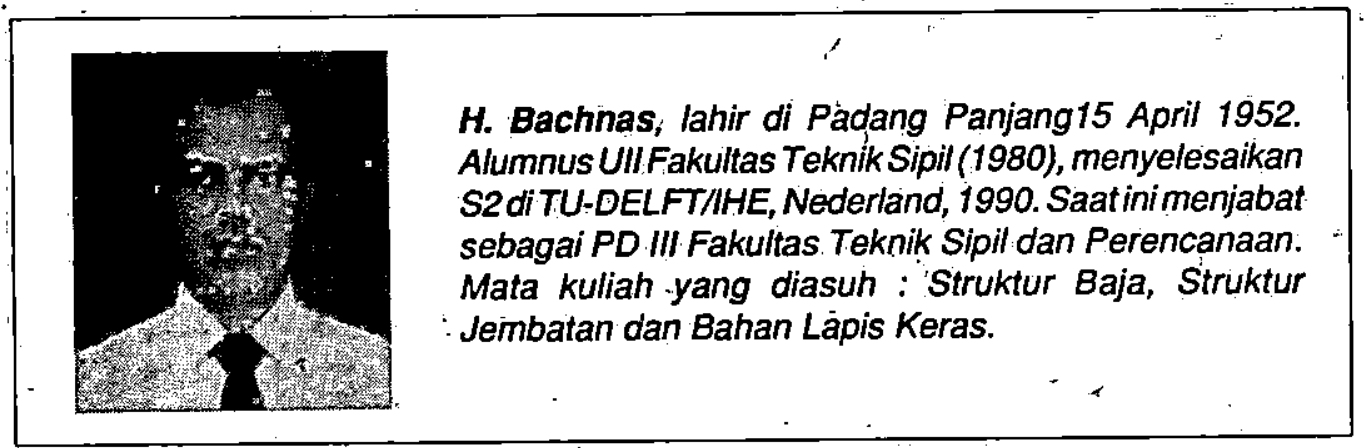

\section{Pendahuluan}

Pada saät sekarang kemajuan teknologi sangat pesat sekali, sudah merambah ke segala bidang aktifițas manusia. Salahsatu dari kemajuạnteknologi tersebut adalah di bidang komputer.

Pada awalnya komputer digunakan sebägai alat bantu dalam perhitungan, hal ini dapat kita lihat dari asal kata komputer yaitu alat/mesin hitung ("TO COMPUTE= MENGHITUNG"). Tetapi sekarang hampir di segàla bidang sudah memanfaatkan jasa komputer sebagai alat bantu yang sangat didambakan seperti dalam hal perbankan, informasi, kesehatan, ekonomi, kemiliteran, teknik administrasi dan lain sebagainya. Kita sudah merasakan hasil proses KTP tingkat Kecamatan dengan komputer dạn suatu saat para pembantu rumah tanggapun akanmenggunakan komputeruntuk melihat daftar menu pada hari ini lengkap dengan bumbu-bumbunya, 'cara memasak dan menyajikannya.'
Komputerdapatmempercepatproses perhitungan dan hasil perhitungan akan lebih terjamin dari kekeliruan, atau dengan kata lain hasil hitungan dengan komputer lebih akurat daripada hasil hitungan dengan cara manual.

Di negara-negara ỳang maju sudah bảnyakmembuat"software" seperti BASIC, TURBO BASIC, PASCAL, TURBO PASCAL, FORTRAN dan banyak lagi bentuk "software" yang sudah beredar di negeri kita. Dengan menggunakan "software" tersebut para tenaga ahli yang berkecimpung di bidang teknik sipil khususnya untuk ilmu mekanika telah membuat beberapa program seperti SAP (structural analysis program), dan MICROFEAF. Keluaran ("output") dari hasil program yang digunakan berupa besaran momen atau gaya-gaya yang bekerja pada konstruksi tersebut.

Untuk keperluan, disain (perencanaan), "output" dari program 
mekanika yạng berupa momen atau gaya batang merupakan data "input" untuk pengolahan lebih lanjut. Biasanya program yang digunakan untuk disain akan disesuaikan dengan jenismaterial yang akan digunakan seperti bahan dari beton, kayu atau baja. Untukmasing-masing jenis bahan yang digunakan sebagai bahän bangunan mempunyai ketentuan-ketentuañ tersendiri yang berlaku pada masing-masing negara, hal ini merupakan dasar pada awal perencanaan.

Program untuk disain yang banyak beredar di negeri kita adalah hasil karya dari negara-negara yangsudahmajuj dengan ketentuan-ketentuan yang sesuai dengan negara mereka. Program-program hasil karya tenaga ahli Indonesia yang sudah disesuaikan dengan ketentuan-ketentuan yang berlaku di negeri kita masih sangat terbatas.

Pemerintah kita sudahmensyaratkan bahwa setiap pengajuan izin perencanaan ("design") harus disesuaikan dengan peraturan dan ketentuan-ketentuan yang berlaku di Indonesia. Dengan alasan tersebut penulis mencoba membuat program HITUNGAN RANGKA BAJA yang disèsuaikan dengan ketentuan yang berlaku dalam PERATURAN PERENCANAAN BANGUNAN BAJA INDONESIA (PPBBI) tahun 1984.

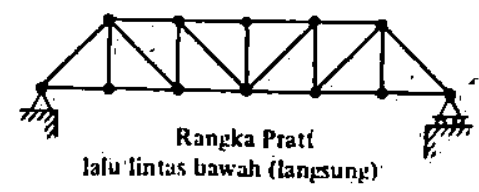

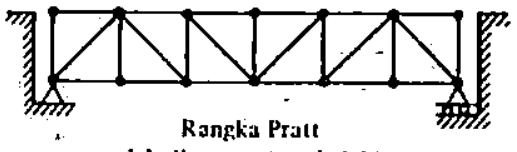

kJiu lintus atas (geladak)
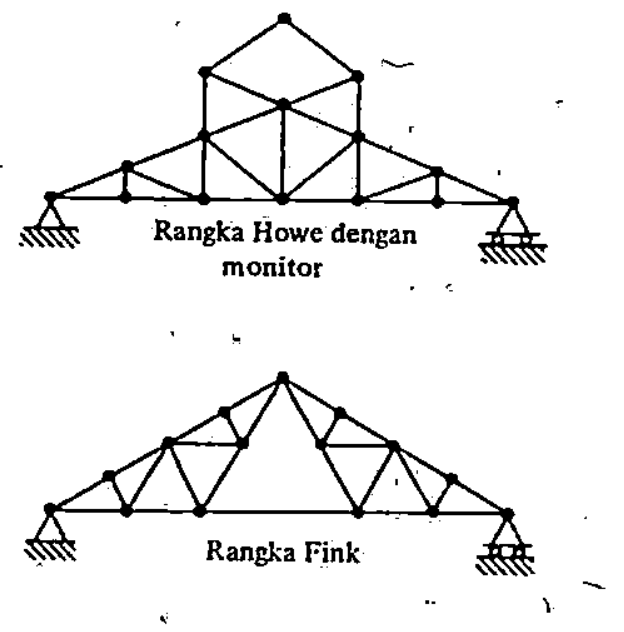

Gambar : Konstruksi Rangka Jembatan dan Atap

\section{Lingkup Permasalahan}

Program yang disajikan ini khusus dibuatuntuk perencanaan bangunan teknik sipil yang menggunakan konstruksi rangka', seperti rangka kuda-kuda untuk bangunan atap dan rangka jembatan atau untuk bangunan-bangunan lainnya yang mènggunakan konstruksi rangka.

Program ini akan menghitung kelangsingan batang dan tegangan yang terjadi pada setiap batang dan memberi tanda pada setiap batang yang dihitung apakah batang tersebut memenuhi ketentuan atau tidak.

Bahan yang digunakan adalah bahan baja sehingga ketentuan-ketentuan yang diberlakukan disesuaikan dengan jenis material yang digunakan dan persyaratan 
yang beriaku di Indonesia.

Karena program ini digunakan untuk mendisain konstruksi rangka baja, maka diperlukan data beban/gaya batang dan panjang batang yang nantinya merupakan "input" untuk program ini dan data tersebut didapat dari hasil "output" program SAP, MICROFEAP atau dari hasil hitungan mekanika secara manual.

\section{Landasan Teori "}

\section{Dasar Perencanaan Konstruksi Baja}

Sebagai dasar perencanaan konstruksi baja adalah mengacu kepada Peraturan Perencanaan Bangunan Baja Indonesia (PPBBI) tahun 1984 dan dengan beberapa anggapan. Padakonstruksi rangka dianggap ujung-ujung batang adalah sendi dan sebagai alat sambung digunakan baut. a. Batang Tarik

Batang tarik adàlah batang dari suatu elemen konstruksi yang menerima beban aksial dengan arah kerja beban pada arah tarik.

Tegangan

$\sigma=\frac{\mathrm{p}}{\mathrm{An}} \leq 0,75 \sigma$

$\sigma=$ tegangan yang terjadi $\mathrm{kg} / \mathrm{cm}^{2}$

$\mathrm{P} \quad=$ gaya batang yang bekerja kg.

An = luas netto tampang batang $\mathrm{cm}^{2}$

$\mathrm{An}=\mathrm{Abr}-\mathrm{A}$ perlemahan pada batang tersebut.

$\bar{\sigma} \quad=$ teganganizin darijenis bahan baja yang digunakan $\mathrm{kg} / \mathrm{cm}^{2}$.

$\bar{\sigma}=\sigma$ luluh $/ 1,5$.

Kelangsingan

$\lambda=\frac{\mathrm{L}}{r \mathrm{i}}, \leq 240$ $\lambda=$ kelangsingan dari batang yang digunakan

$\mathrm{L}=$ panjang batang tarik $\mathrm{cm}$.

$\mathrm{i}=$ jari-jari kelembaman $\mathrm{cm}$, biasanya harga i minimum sudah tersedia dalam daftar profil berdasarkan profil yang digunakan atau dapat juga dihitung berdasarkan numus berikut ini :

$\mathrm{i}=\sqrt{\frac{\operatorname{Imin}}{\mathrm{A}}}$

Imin $=$ momen inersia minimum dari profil yang digunakan $\mathrm{cm}^{4}$

$\mathrm{A}=$ luas tampang profil batang tarik $\mathrm{cm}^{2}$

\section{b. Batang Desak}

Batang desak adalah batang dari suatu elemen konstruksi yang menerima beban aksial dengan arah kerja beban mendesak batang tersebut.

Tegangan.

$$
\sigma=\omega * \frac{P}{A} \leq \vec{\sigma}
$$

$\sigma \quad=$ tegangan desak yang terjadi $\mathrm{kg} /$ $\mathrm{cm}^{2}$

$\omega=$ faktor tekuk yang tergantung dari kelangsingan batang yang digunakan dan faktor tekuk ini juga dipengaruhi oleh jenis baja yang digunakan. Harga dari faktor tekuk tersebut dapat dihitung dengan persamaan dibawah ini.

$\omega=1$, jika harga : $\lambda s \leq 0.183$

$\omega=\frac{1,41}{1,593-\lambda s}$, jika harga $: 0.183<\lambda s<1$

$\omega=2,381 * \lambda s^{2}$, jika harga $: \lambda s \geq 1$

Kelangsingan.

$\lambda s=\frac{\lambda}{\lambda g}$ 
$\lambda=\frac{\mathrm{Lk}}{\mathrm{i} \min }$

$\lambda=$ kelangsingan batang desak

$\mathbf{L k}=$ panjjang tekukbatang desak, dalam hal ini diambil sama dengan panjang batang desak. karena ujung-ujung batang dianggap sendi-sendi sehingga harga angka

i $\min =$ tekuk sama dengan 1.

jari-jari kelembaman minimüm dari profil yang digunakan $\mathrm{cm}$.

$\begin{aligned} \lambda \mathrm{g}= & \pi * \sqrt{\frac{\mathrm{E}}{0.7^{*} \sigma 1^{*}}} \\ \mathrm{E}= & \begin{array}{l}\text { modulus elastis dari jenis baja } \\ \text { yang digunakan, biasanya dipakai } \\ \text { sebesar } 2,1 * 10^{5} \mathrm{~kg} / \mathrm{cm}^{2}\end{array} \\ \sigma 1= & \begin{array}{l}\text { teganganluluh darijenis baja yang } \\ \text { digunakan } \mathrm{kg} / \mathrm{cm}^{2}\end{array}\end{aligned}$

\section{Dasar Pemprograman}

Dasar pemprograman páda program konstruksi rangka baja ini menggunakan "software" FORTRAN dan sebagai pèngolah kata ("wordprosessing") pada penulisan program menggunakan NE (NORTON EDITOR).

\section{Cara Pemakaian Program}

Program yang akan digunakan ini terdiri dari tiga bagian utama, yaitu "input" data, proses dan "output" yang merupakan hasil dari pemprosesan program.

"Input" data ada dua macam, yang pertama merupakan data gaya batang dan panjang batang yang didapat dari hasil hitungan mekanika dengan proses komputer seperti hasil "output" program SAP atau dari hasil 'program MICROFEAP maupun dari hasil hitungan dengan cara manual. Dataini dimasukkan dalam suatu data "file" yang diberi nama BAJA.DAT penulisan data ini dapat menggunakan NORTON EDITOR (NE). Penulisan data pertama . adalahmenuliskan jumlah batang yang akan diproses dan berikutnya adalah penulisan gaya batang dan bersamaan dengan gaya batang juga dituliskan panjang batang. Untuk gaya batang yang mengalami desak ditulis dengan tanda negatip (-) dan untuk gaya batang, yang memikul beban tarik ditulis dengan tanda positip (+) atau boleh jugà tidak ditulis (+) nya (lampiran 1):

Sebagai contoh :

pada baris 1 ditulis

pada baris 2 ditulis

$61:$

pada baris 3 ditulis

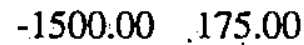
dan seterusnya.

$2750.75 \quad 187.50$

Keterangan :

61 --> 61 buah batang yang akan diproses

$-1500.00175 .00-\rightarrow$ beban desak $=1500,00 \mathrm{~kg}$ panjang batang $=175,00 \mathrm{~cm}$

2750.75187 .50 - $>$ beban tarik $=2750,75 \mathrm{~kg}$ panjang batang $=187,50 \mathrm{~cm}$.

Input data yang kedua adalah.pada saat menjalankan program, akan keluar. beberapapertanyaan yang berkaitan dengan jenis baja yang digunakan, luasan dari profil yang digunakan untuk batang desak, batang tarik dan jari-jari kelembaman dari masingmasing profil yang digunakan tersebut.

Pada saat pemprosesan, program akan membaca data dari file data dan membaca data input melalui "keyboard",, data tersebut akan diolah sesuai dengan perintah-perintah program.- Untuk lebih jelasnya dapat dilihat pada "flowchart" (diagram alur) dari program tersebut (lampiran 2).

Keluaran ("output:") dari proses' secara otomatis akan dimasukkan pada file 
tersendiri dengan nama BAJA.OUT. File ini dapat dibuka dengan menggunakan NE (Norton Editor), data yang nampak dapat dicetak melalui "printer" dan jika ada kesalahan dapat dikoreksi ulang melalui input data.

Hasil yang disajikan dari program ini sudah berupa tabel (dapat dilihat páda lampiran 3). Hasil olahan program, penjelasan dari "output" sebagai berikut:

- pada bagian atas tabel menampilkan "input" yang dimasukkan melalui "keyboard" mengenai tegangan luluh, tegangan izin untuk batang tarik dan desak hasil olahan program, luasan profil untuk batang desak dan tarik, dan juga jari-jari kelembaman untuk batang desak dan tarik.

= pada bagian atas tabel tertera nomor rangka yang diolah sesuai dengan nomor rangka yang dimasukkan pada saat "input" data.

- pada kolom pertama No.BAT. hal ini menjelaskan nomorurut dari batangpada konstruksi rangka tersebut, jumlah dari batang tersebut akan diolaholeh program sesuai dengan data yang terdapat pada file data (BAJA.DAT).

- kolom kedua tertulis BEBAN (KG) maksudnyà adalah menampilkan kembali besar beban pada tiap-tiap batang dari konstruksi rangka yang datanya telah dimasukkan pada file BAJA.DAT. Beban yang ditampilkan dalam Kilogram (kg) dan ada dua tanda yang tertera, tanda negatip (-) untuk beban desak dan tanda positip untuk beban tarik, sedangkan untuk batang yang tidak mempunyai beban akan dilihatkan dengan angka .00 dan pada "input" data batang ini harus diberi tanda positip dan angka 0.00 .Jadi pada kolom ini tidak ada pengolahan data oleh program.

- pada kolom ketiga ditampilkan tulisan PANJANG (CM) maksud dari tulisan ini adalah mencantumkan panjang masing-masing batang dalam satuan $\mathrm{cm}$. Data ini didapat sesuai dengan data yang dimasukkan pada file data BAJA.DAT, berarti pada kolom ini tidak ada pengolahan data oleh program.

- padakolom keempat ditampilkan tulisan KELANGSINGAN maksud dari tulisan ini untuk melihatkan besarnya kelangsingan dari masing-masing batang. Pada kolom ini terdapat dua kolom yang masing-masing kolom tertulis L/i dan KET. Nilai yang dituliskan pada kolom yang pertama adalah hasil olahan program, jika hasil olahan tersebut melewati dari batasan yang sudah ditentukan untuk batang desak sebesar 200 dan batang tarik 240 , maka hasil olahan program akan menampilkan padakolom KET, dengan tulisan $>200$ untuk batang desak dan $>240$ untuk batang tarik. Dari hasil olahan ini dapat dievaluasi bahwaukuran dari profil yang digunakan tidak memenuhi syarat sehingga perlu adanya perubahan ukuran profil, dan jika terjadi kelangsingan batang melebihi persyaratan maka untuk selanjutnya batang tersebut tidak akan diolah oleh program, program secara otomatis akan memproses batang yang berikutnya.

- kolom kelima menampilkan tulisan TEGANGAN ( $\left.\mathrm{KG} / \mathrm{CM}^{2}\right)$, kolom ini akan mencantumkan nilai tegangan dari masing-masing batang hasil olahan program dalam satuan $\mathrm{kg} / \mathrm{cm}^{2}$ Pada 
kólom ini tersedia empat kolom, dua kolom pertama untuk olahan tegangan pada batang desak dan dua kolom berikutnya untuk batang tarik. Jika hasil olahan program untuk masing-masing batang tersebut melebihi persyaratan yaitu tegangan izin untuk batang desak maupun batang tarik, maka pada kolom KET. akan tertulis >S.IZ. Hasil yang ditampilkan padakolom kelima ini dapat sebagai kesimpulan dari perhitungan bahwa profil yang digunakan amañ atau tidak aman untuk memikul beban yang bekerja pada batang tersebut.

\section{Kesimpulan}

Program ini sangat membantu.para teknisi dilapangan dan para mahasiswa teknik sipil dalam menghadapi perencanaan konstruksi rangka batang, karena biasanya padaperencanaan rangka batang dalam satu rangka terdapatpuluhan batang dan masingmasing batang harus ditinjau kekuatannya. Pelaksanaan perençanaan dengan cara manual akan memerlukan waktu yang cukup lama dan ketelitian. Dengan menggunäkan program ini akan dapat menghemat waktu dan mempunyai tingkat ketelitian yang lebih, sehingga "trial and error" untuk pemilihan profil dapat dikerjakan dengan cepat dan setiap pemilihan profil dapat diarsipkan sebagai dokumen.

\section{Saran}

Tiap-tiap negara mempunyai peraturan tersendiri dalam mensyaratkan suatu perencanaan, tentu program yang dibuat oleh para ahli suatù negara akan disesuaikan dengan ketentuan pada negara mereka. Dengan demikian kita harus teliti dalam menggunakan program hasil karya negara lain apakah program tersebut sesuai dengan persyaratan yang berlaku di Indonesia. Dan sebaliknya para tenaga ahli membuat sendiri program yang sesuai dengan syarat-syarat yang berlaku di tempat kita.

\section{Daftar Pustaka}

1984, Peraturan Perencanaan

Bangunan Baja Indonesia, Yayasan Lembaga Penyelidikan Masalah Bangunan, Bandung. 1991, Struktur Baja I, Paguyuban Dosen Baja Yogyakarta, Yogyakarta.

Bustrảan, Z. Lambri. 1990, Daftar-daftar untuk Konstruksi Baja, PT Pradnya Paramita, Jakarta.

Ekó Nugroho, F.Soesianto, 1984, Bahasa Fortran, Andi Offset Yogyakarta, Yogyakarta. 


\section{LAMPIRAN 1}

C PERHITUNGA N TEGANGAN UNTUK RANGKA BAJA

C

REAL LAM,LAMG,LAMS,SIGL,SIGIZ,SIG,B,P,W

C INTEGER N.J

OPEN (3,FILE='BAJA.OUT)

OPEN (6,FILE='BAJA.DAT)

READ (6,")N

READ( :)A

READ $\because$ AN

READ(* ")SIGL.

READ(*;)R

READ(**)J

C

$$
\begin{gathered}
\text { HITUNGAN TEGANGAN IZIN } \\
\text { SIGIZ }=\text { SIGL } 11.5 \\
\text { SIGIZT }=\text { SIGIZ*0.75 }
\end{gathered}
$$

C

C PERHITUNGAN

C

DO $40 !=1, N$

SIG $=0.0$

SIGT $=0.0$

LAMS $=0.0$

$W=0.0$

$B=0.0$

$P=0.0$

READ(6,'(19.2,1X,16.2)')B,P IF(B.GT.O) GOTO 75

$L A M=P / R$

IF (LAM.GT.200) GOTO 40

IF (B.EQ.0) GOTO 40

LAMG $=3.14^{*}(2100000 / 0.7 / \mathrm{SIGL}) * 0.5$

LAMS = LAMS/LAMG

IF(LAMS.LE.0.183) GOTO 50

IF(LAMS.LT.1) GOTO 60

$W=2.381 *$ LAMS * LAMS

$50 \quad W=1$ GOTO 70

GOTO 70

$60 \quad W=1.41 /(1.593-$ LAMS $)$

70. $\quad$ SIG $=W^{*}(-1)^{*} B / A$

$75 \quad$ LAMT $=$ P/R IF(LAMT.GT.240) GOTO 40

40

$$
S I G T=B / A N
$$

CONTINUE

close (3)

close (6)

WRITE (" ")' SELESAI '

END 


\section{LAMPIRAN 2}

Contoh Input Data

61

\begin{tabular}{|c|c|c|c|c|}
\hline-446.00 & 251.25 & & -1880.00 & 150.00 \\
\hline-446.00 & 251.25 & & -1712.00 & 140.00 \\
\hline-1025.00 & 173.20 & & -1712.00 & 140.00 \\
\hline 2050.00 & 173.20 & & -1880.00 & 150.00 \\
\hline 3905.00 & 173.20 & & 602.00 & 202.96 \\
\hline 3308.00 & 150.00 & & 249.00 & 265.44 \\
\hline 3308.00 & 140.00 & & -217.00 & 200.00 \\
\hline 3308.00 & 140.00 & & 249.00 & 265.44 \\
\hline 3905.00 & 150.00 & & 603.00 & 202.96 \\
\hline 2050.00 & 173.20 & & -1122.00 & 174.53 \\
\hline-1025.00 & 173.20 & & -1122.00 & 174.53 \\
\hline-446.00 & 251.25 & & -397.00 & 173.54 \\
\hline-446.00 & 251.25 & & 468.00 & 300.00 \\
\hline 0.00 & 84.50 & & -397.00 & 173.54 \\
\hline-562.00 & 158.22 & & 512.00 & 144.25 \\
\hline-3599.00 & 169.00 & & 1024.00 & 144.25 \\
\hline 3038.00 & 171.14 & . & -2050.00 & 173.20 \\
\hline-562.00 & 158.22 & & -4509.00 & 173.20 \\
\hline-3599.00 & 169.00 & & -2856.00 & 230.93 \\
\hline-3000.00 & 169.00 & & -1145.00 & 173.21 \\
\hline 2430.00 & 171.14 & & -735.00 & 173.21 \\
\hline-145.00 & 169.00 & & -735.00 & 173.21 \\
\hline-900.00 & 225.97 & & -1145.00 & 173.21 \\
\hline 673.00 & 169.00 & & -2856.00 & 230.94 \\
\hline-103.00 & 219.46 & & -4509.00 & 173.20 \\
\hline 159.00 & 169.00 & & -2050.00 & 173.20 \\
\hline-103.00 & 219.46 & & 1024.00 & 144.25 \\
\hline 673.00 & 169.00 & & 512.00 & 144.25 \\
\hline-900.00 & 225.97 & & & \\
\hline-145.00 & 169.00 & & & \\
\hline 2430.00 & 171.14 & & & \\
\hline-3000.00 & 169.00 & & & \\
\hline 3038.00 & 171.14 & & & \\
\hline-3599.00 & 169.00 & & & \\
\hline-562.00 & 158.22 & & & \\
\hline 0.00 & 84.50 & & & \\
\hline
\end{tabular}




\section{Lampiran 3}

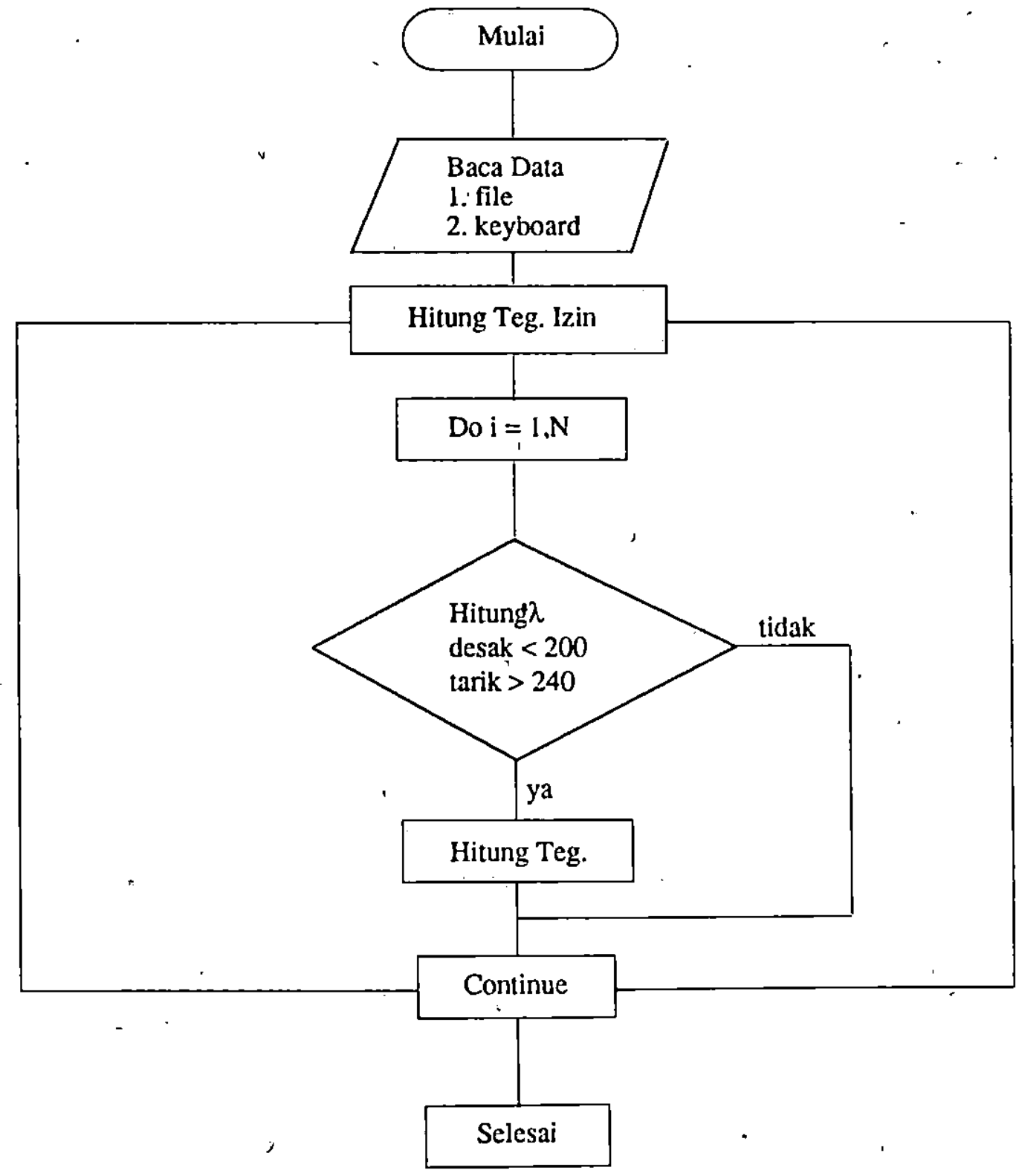

Gambar Flowchart Hitungan Rangka Batang 
Lampiran : 4

Contoh : Out Put Data

LUAS TOTAL PROFIL BAT. TEKAN (CM2) $\quad \equiv 10.70$

LUAS TOTAL PROFIL BAT.TARIK (CM2) $\quad r=7.60$

TEGANGAN LULUH BAJA (KG/CM2) $\quad=2100.00$

TEGANGAN IZIN TARIK BAJA (KG/CM2) $\quad=1400.00$

JARIJARI KELEMBABAN BT. DESAK (CM) $=1.10$

JARI-JARI'KELEMBABAN BT. TARIK (CM) $=76$

RANGKA NO. 7

\begin{tabular}{|c|c|c|c|c|c|c|c|c|}
\hline \multirow{2}{*}{$\begin{array}{l}\text { NO. } \\
\text { BAT. }\end{array}$} & \multirow{2}{*}{$\begin{array}{l}\text { BEBAN } \\
\text { (KG) }\end{array}$} & \multirow{2}{*}{$\begin{array}{l}\text { PANJANG } \\
\text { (CM) }\end{array}$} & \multicolumn{2}{|c|}{ "KELANGSINGAN } & \multicolumn{4}{|c|}{ TEGANGAN (KG/CM2) } \\
\hline & & & Li & KET & DESAK & KET. & TARIK & KET. \\
\hline 1 & -446.00 & 251.25 & 228.41 & $>200$ & -.' & -- & -- & -- \\
\hline 2 & -446.00 & 251.25 & 228.41 & $>200$ & - & - & - & - \\
\hline 3 & -1025.00 & 173.20 & 157.45 & - & 401.47 & - & - & - \\
\hline 4 & 2050.00 & 173.20 & 157.45 & - & - & - & 269.74 & - \\
\hline 5 & 3905.00 & 150.00 & 157.45 & - & - & - & 513.82 & - \\
\hline 6 & 3308.00 & 140.00 & 157.45 & - & - & - & 435.26 & - \\
\hline 7 & 3308.00 & 140.00 & 157.45 & - & - & $\therefore$ & 435.26 & - \\
\hline 8 & 3905.00 & 173.20 & 157.45 & - & - & - & 513.82 & - \\
\hline 9 & 2050.00 & 173.20 & 157.45 & - & - & - & $269: 74$ & - \\
\hline 10 & -1025.00 & 173.20 & 157.45 & - & 401.47 & $\therefore$ & 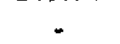 & . \\
\hline 11 & -446.00 & 251.25 & 228.41 & $>200$ & $=$ & - & - & - \\
\hline 12 & -446.00 & 251.25 & $228: 41$ & $>200$ & - & - & . & - \\
\hline 13 & .00 & $84.50^{\circ}$ & 76.82 & - & - & $=$ & - & - \\
\hline 14 & -562.00 & 158.22 & 143.84 & $\because$ & 183.69 & - & - & - \\
\hline 15 & -3599.00 & 169.00 & 153.64 & - & 1342.10 & - & - & - \\
\hline 16 & 3038.00 & 171.14 & 153.64 & - & - & - & 339.74 & - \\
\hline 17 & -300.00 & 169.00 & 153.64 & - & 1118.73 & - & - & - \\
\hline 18 & 2430.00 & 171.14 & 153.64 & - & .54 .07 & - & .- & - \\
\hline 19 & -145.00 & 169.00 . & 153.64 & - & - & - & & - \\
\hline 20 & -900.00 & 225.97 & 205.43 & $>200$ & - & . & - & - \\
\hline 21 & 673.00 & 169.00 & 205.43 & - & $=$ & - & 88.55 & - \\
\hline 22 & -103.00 & 219.46 & 199.51 & - & 64.77 & - & - & - \\
\hline 23 & 159.00 & 169.00 & 199.51 & - & $\because$ & - & 20.92 & - \\
\hline 24 & -103.00 & 219.46 & 199.51 & - & 64.77 & - & $-\cdot$ & - \\
\hline 25 & 673.00 & 169.00 & 199.51 & - & - & - & 88.55 & - \\
\hline 26 & -900.00 & 225.97 & 205.43 & $>200$ & $=$ & . & - & - \\
\hline 27 & -145.00 & 169.00 & 153.64 & - & 54.07 & - & - & .- \\
\hline 28 & 2430.00 & 171.14 & 153,64 & - & - & . & 319.74 & - \\
\hline 29 & -3000.00 & 169.00 & 153.64 & - & 1.118 .73 & - & - & - \\
\hline 30 & 3038.00 & 171.14 & 153.64 & - & - & - & 399.74 & - \\
\hline 31 & -599.00 & 169.00 & 153.64 & - & 1342.10 & - & - & - \\
\hline 32 & -562.00 & 158.22 & 143.84 & - & 183.69 & 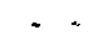 & - & - \\
\hline 33 & .00 & 84.50 & 76.82 & - & $=$ & - & - & - \\
\hline 34 & -1880.00 & 150.00 & 136.36 & 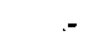 & .552 .29 & - & - & - \\
\hline 35 & -1712.00 & 140.00 & 127.27 & - & 438.12 & - & - & : \\
\hline 36 & -1712.00 & 140.00 & 127.27 & - & 438.12 & - & , & - \\
\hline
\end{tabular}


Bachnas, Program Komputer sebagai Perencanaan Rangka Batang Baja

\begin{tabular}{l|r|r|r|r|r|r|r|r}
\hline \hline & \\
37 & -1880.00 & 150.00 & 136.36 & - & 552.29 & - & - & - \\
38 & 602.00 & 202.96 & 267.05 & $>240$ & - & - & - & - \\
39 & 249.00 & 265.44 & 349.26 & $>240$ & - & - & - & - \\
40 & -217.00 & 200.00 & 181.82 & - & 113.33 & - & - & - \\
41 & 249.00 & 265.44 & 349.26 & $>240$ & - & - & - & - \\
42 & 603.00 & 202.96 & 267.05 & $>240$ & - & - & - & - \\
43 & -1122.00 & 174.53 & 158.66 & - & 446.23 & - & - & - \\
44 & -1122.00 & 174.53 & 158.66 & - & 446.23 & - & - & - \\
45 & -397.00 & 173.54 & 157.76 & - & 156.11 & - & - & - \\
46 & 468.00 & 300.00 & 394.74 & $>240$ & - & - & - & - \\
47 & -397.00 & 173.54 & 157.76 & - & 156.11 & - & - & - \\
48 & 512.00 & 144.25 & 157.76 & - & - & - & 67.37 & - \\
49 & 1024.00 & 144.25 & 157.76 & - & - & - & 134.74 & - \\
50 & -2050.00 & 173.20 & 157.45 & - & 802.93 & - & - & - \\
51 & -4509.00 & 173.20 & 157.73 & - & 1766.06 & $>S .1 Z$ & - & - \\
52 & -2856.00 & 230.94 & 209.95 & - & - & - & - & - \\
53 & -1145.00 & 173.21 & 157.46 & $>200$ & 448.52 & - & - & - \\
54 & -735.00 & 173.21 & 157.46 & - & 287.91 & - & - & - \\
55 & -735.00 & 173.21 & 157.46 & - & 287.91 & - & - & - \\
56 & -1146.00 & 173.21 & 157.46 & - & 448.52 & - & - & - \\
.57 & -2856.00 & 230.94 & 209.95 & $>200$ & - & - & - & - \\
58 & -4509.00 & 173.20 & 157.45 & - & 1766.06 & $>S .1 Z$ & - & - \\
59 & -2050.00 & 173.20 & 157.45 & - & 802.93 & - & - & - \\
60 & 1024.00 & 144.25 & 157.45 & - & - & - & 134.74 & - \\
61 & 512.00 & 144.25 & 157.45 & - & - & - & 67.37 & - \\
& & & & & & & & \\
\hline
\end{tabular}

